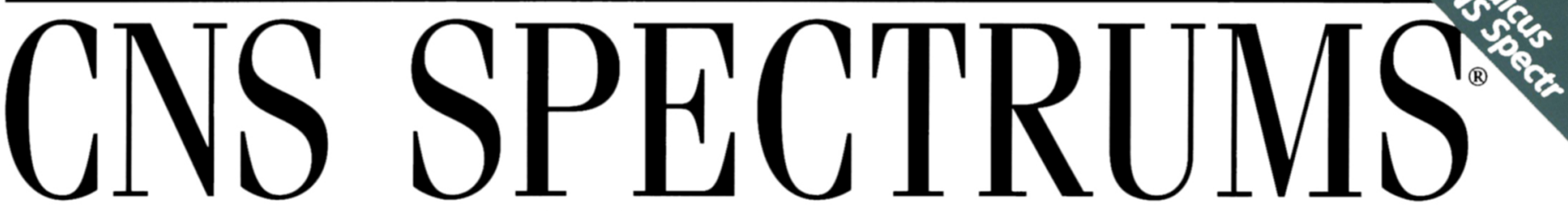

The International Journal of Neuropsychiatric Medicine

\title{
10
}

\section{Personality Disorders}

Guest Editor-Larry J. Siever, MD

\author{
INTRODUCTION \\ Refining the Approaches to Personality Disorders \\ L.J. Siever \\ ORIGINAL RESEARCH \\ Neurobiologic Function and Temperament \\ in Subjects With Personality Disorders \\ V. Mitropoulou, R.L. Trestman, A.S. New, \\ J.D. Flory, J.M. Silverman, and L.J. Siever \\ Abuse and Neglect in Childhood: \\ Relationship to Personality Disorder Diagnoses \\ L.M. Bierer, R. Yehuda, J. Schmeidler, V. Mitropoulou, \\ A.S. New, J.M. Silverman, and L.J. Siever \\ Norepinephrine Function in \\ Personality Disorder: \\ Plasma Free MHPG \\ Correlates Inversely With \\ Life History of Aggression \\ E.F. Coccaro, R. Lee, and M. McCloskey \\ Relationship of Personality to \\ Dissociation and Childhood Trauma \\ in Borderline Personality Disorder \\ D. Simeon, D. Nelson, R. Elias, \\ J. Greenberg, and E. Hollander
}

The Role of Childhood Trauma in Differences in Affective Instability in Those With Personality Disorder

M. Goodman, D.S. Weiss, H. Koenigsberg,

V. Kotlyarevsky, A.S. New, V. Mitropoulou,

J.M. Silverman, K. O'Flynn, and L.J. Siever

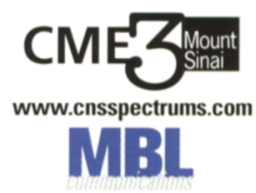




\section{Time for wakefulness}

PROVIGIL ${ }^{\circledR}$ (modafinil) TABLETS

BRIEF SUMMARY: Consult Package Insert for Complete Prescribing Information

INDICATIONS and USAGE: To improve wakefulness in patients with excessive daytime sleepiness associated with narcolepsy.

\section{CONTRAINDICATIONS: Known hypersensitivity to PROVIGIL}

PRECAUTIONS: General: Patients should be cautioned about operating an automobile or other hazardous machinery until they are reasonably certain that PROVIGIL therapy will not adversely affect their ability to engage in such activities.

Cardiovascular System: In clinical studies of PROVIGIL, signs and symptoms including chest pain, palpitations, dyspnea, and transient ischemic T-wave changes on ECG were observed in 3 subjects in association with mitral valve prolapse or left ventricular hypertrophy. It is recommended that PROVIGIL tablets not be used in patients with a history of left ventricular hypertrophy or ischemic ECG changes, chest pain, arrhythmia or other clinically significant manifestations of mitral valve prolapse in association with CNS stimulant use. Patients with a recent history of Ml or unstable angina should be treated with caution. Periodic monitoring of hypertensive patients taking PROVIGIL may be appropriate.

Central Nervous System: Caution should be exercised when PROVIGIL is given to patients with a history of psychosis. Patients with Severe Renal Impairment: Treatment with PROVIGIL resulted in much higher exposure to its inactive metabolite, modafinil acid, but not PROVIGIL itself.

Patients with Severe Hepatic Impairment: PROVIGIL should be administered at a reduced dose because its clearance is decreased.

Patients Using Contraceptives: The effectiveness of steroidal contraceptives may be reduced when used with PROVIGIL and for 1 month after discontinuation. Alternative or concomitant methods of contraception are recommended during and for 1 month after treatment.

Information for Patients: Physicians are advised to discuss the following with patients taking PROVIGIL: Pregnancy: Animal studies to assess the effects of PROVIGIL on reproduction and the developing fetus were not conducted so as to ensure a comprehensive evaluation of the potential of PROVIGIL to adversely affect fertility, or cause embryolethality or teratogenicity. Patients should notity their physician if they become pregnant or intend to become pregnant during therapy. They should be cautioned of the potential increased risk of pregnancy when using steroidal contraceptives (including depot or implantable contraceptives) with PROVIGIL and for 1 month after discontinuation. Nursing: Patients should notify their physician if they are breast feeding. Concomitant Medication: Patients should inform their physician if they are taking or plan to take any prescription or over-the-counter drugs, because of the potential for drug interactions. Alcohol: It is prudent to avoid alcohol while taking PROVIGIL. Allergic Reactions: Patients should notity their physician if they develop a rash, hives, or a related allergic phenomenon.

Drug Interactions: CNS Active Drugs: In a single-dose study, coadministration of PROVIGIL $200 \mathrm{mg}$ with methyiphenidate $40 \mathrm{mg}$ delayed the absorption of PROVIGIL by approximately 1 hour. The coadministration of a single dose of clomipramine $50 \mathrm{mg}$ with PROVIGIL $200 \mathrm{mg} /$ day did not affect the pharmacokinetics of either drug. One incident of increased levels of clomipramine and its active metabolite desmethylclomipramine has been reported. In single-dose study with PROVIGIL (50,100 or $200 \mathrm{mg}$ ) and triazolam $0.25 \mathrm{mg}$, no clinically important alterations in the safety profile of either drug were noted. In the absence of interaction studies with monoamine oxidase (MAO) inhibitors, caution should be exercised Potential Interactions with Drugs That Inhibit, Induce, or Are Metabolized by Cytochrome P-450 Isoenzymes and Othe Hepatic Enzymes: Chronic dosing of PROVIGIL $400 \mathrm{mg} / \mathrm{da}$ resulted in $\sim 20 \%$ mean decrease in PROVIGIL plasma trough concentration suggesting that PROVIGIL may have caused induction of its metabolism. Coadministration of potent inducers of CYP3A4

(eg. carbamazepine, phenobarbital, rifampin) or inhibitors of CYP3A4 (eg, ketoconazole, itraconazole) could alter the levels of PROVIGIL. Caution needs to be exercised when PROVIGIL is coadministered with drugs that depend on hepatic enzymes for their clearance; some dosage adjustment may be required. Potentially relevant in vivo effects of PROVIGIL based on in vitro data are:

A slight induction of CYP1A2 and CYP2B6 in a concentration-dependent manner has been observed. A modest induction of CYP3A4 in a concentration-dependent manner may result in lower levels of CYP3A4 substrates (eg, cyclosporine, steroidal contraceptives, theophylline)

An apparent concentration-related suppression of expression of CYP2C9 activity may result in higher levels of CYP2C9 substrates (eg, warfarin, phenytoin).

A reversible inhibition of CYP2C19 may result in higher levels of CYP2C19 substrates (eg, diazepam, propranolol, phenytoin, S-mephenytoin)

In some patients deficient in CYP2D6, the amount of metabolism via CYP2C19 may be substantially larger Co-therapy with PROVIGIL may increase levels of some tricyclic antidepressants (eg, clomipramine, desipramine).

\section{Carcinogenesis, Mutagenesis, Impairment of Fertility}

Carcinogenesis: The highest dose studied in carcinogenesis studies represents 1.5 times (mouse) or 3 times (rat) the maximum recommended human daily dose of $200 \mathrm{mg}$ on a $\mathrm{mg} / \mathrm{m}^{2}$ basis. There was no evidence of tumorigenesis associated with PROVIGIL administration in these studies, but because the mouse study used an inadequate high dose below that representative of a maximum tolerated dose, the carcinogenic potential in that species has not been fully evaluated. Mutagenesis: There was no evidence of mutagenic or clastogenic potential of PROVIGIL. Impairment of Fertility: When PROVIGIL was administered orally to male and female rats prior to and throughout mating and gestation at up to $100 \mathrm{mg} / \mathrm{kg} / \mathrm{day}$ ( 4.8 times the maximum recommended daily dose of $200 \mathrm{mg}$ on a mg/m² basis) no effects on fertility were seen. This study did not use sufficiently high doses or large enough sample size to adequately assess effects on fertility.

Pregnancy: Pregnancy Category C: Embryotoxicity was observed in the absence of maternal toxicity when rats received oral PROVIGIL throughout the period of organogenesis. At $200 \mathrm{mg} / \mathrm{kg} / \mathrm{day}$ (10 times the maximum recommended daily human dose of $200 \mathrm{mg}$ on a mg/m² basis) there was an increase in resorption, hydronephrosis, and skeletal variations. The no-effect dose for these effects was $100 \mathrm{mg} / \mathrm{kg} / \mathrm{day}$ ( 5 times the maximum recommended daily human dose on a $\mathrm{mg} / \mathrm{m}^{2}$ basis). When rabbits received ora PROVIGIL throughout organogenesis at doses up to $100 \mathrm{mg} / \mathrm{kg} /$ day (10 times the maximum recommended daily human dose on a $\mathrm{mg} / \mathrm{m}^{2}$ basis), no embryotoxicity was seen. Neither of these studies, however, used optimal doses for the evaluation of embryotoxicity. Although a threshold dose for embryotoxicity has been identified, the full spectrum of potential toxic effects on the fetus has not been characterized. When rats were dosed throughout gestation and lactation at doses up to $200 \mathrm{mg} / \mathrm{kg} /$ day, no developmental toxicity was noted post-natally in the offspring. There are no adequate and well-controlled trials with PROVIGIL in pregnant women. PROVIGIL should be used during pregnancy only if the potential benefit outweighs the potential risk.
Labor and Delivery: The effect of PROVIGIL on labor and delivery in humans has not been systematically investigated. Seven normal births occurred in patients who had received PROVIGIL during pregnancy. Nursing Mothers: It is not known whether PROVIGIL or its metabolite are excreted in human milk. Caution should be exercised when PROVIGIL is administered to a nursing woman.

PEDIATRIC USE: Safely and effectiveness in individuals below 16 years of age have not been established. GERIATRIC USE: Safety and effectiveness in individuals above 65 years of age have not been established. ADVERSE REACTIONS: PROVIGIL has been evaluated for safety in over 2200 subjects, of whom more than 900 subjects with narcolepsy or narcolepsy/hypersomnia were given at least 1 dose of PROVIGIL. In controlled clinical trials, PROVIGIL was well tolerated, and most adverse experiences were mild to moderate. The most commonly observed adverse events ( $\geq 5 \%$ ) associated with the use of PROVIGIL more frequently than placebo-treated patients in controlled US and foreign studies were headache, infection, nausea, nervousness, anxiety, and insomnia. In US controlled trials, $5 \%$ of the 369 patients who received PROVIGII discontinued due to an adverse experience. The most frequent $(\geq 1 \%)$ reasons for discontinuation that occurred at a higher rate for PROVIGIL than placebo patients were headache $(1 \%)$, nausea $(1 \%)$, depression $(1 \%)$ and nervousness $(1 \%)$. The incidence of adverse experiences that occurred in narcolepsy patients at a rate of $\geq 1 \%$ and were more frequent in patients treated with PROVIGIL than in placebo patients in US controlled trials are listed below. Consult full prescribing information on adverse events.

Body as a whole: Headache,' chest pain, neck pain, chills, rigid neck, fever/chills

Digestive: Nausea,' diarrhea, 'dry mouth,' anorexia,' abnormal liver function,', vomiting, mouth ulcer, gingivitis, thirst Respiratory system: Rhinitis, ${ }^{1}$ pharyngitis, ' lung disorder, dyspnea, asthma, epistaxis

Nervous system: Nervousness,' dizziness, depression, anxiety, cataplexy, insomnia, paresthesia,

dyskinesia, ${ }^{3}$ hypertonia, confusion, amnesia, emotional lability, ataxia, tremor

Cardiovascular: Hypotension, hypertension, vasodilation, arrhythmia, syncope

Hemic/Lymphatic: Eosinophilia

Special senses: Amblyopia, abnormal vision

Metabolic/Nutritional: Hyperglycemia, albuminuria

Musculo-skeletal: Joint disorder

Skin/Appendages: Herpes simplex, dry skin

Urogenital: Abnormal urine, urinary retention, abnormal ejaculation

IIncidence $\geq 5 \%,{ }^{2}$ Elevated liver enzymes ${ }^{3}$ Oro-facial dyskinesias, ${ }^{4}$ Incidence adjusted for gender.

Dose Dependency: In US trials, the only adverse experience more frequent ( $\geq 5 \%$ difference) with PROVIGIL $400 \mathrm{mg} /$ day than PROVIGIL $200 \mathrm{mg} /$ day and placebo was headache.

Vital Signs Changes: There were no consistent effects or patterns of change in vital signs for patients treated with PROVIGIL in the US trials.

Weight Changes: There were no clinically significant differences in body weight change in patients treated with PROVIGIL compared to placebo.

Laboratory Changes: Mean plasma levels of gamma-glutamyl transferase (GGT) were higher following administration of PROVIGIL but not placebo. Few subjects (1\%) had GGT elevations outside the normal range. Shitt to higher, but not clinically significantly abnormal, GGT values appeared to increase with time on PROVIGIL. No differences were apparent in alkaline phosphatase, alanine aminotransferase, aspartate aminotransferase total protein, albumin, or total bilirubin. There were more elevated eosinophil counts with PROVIGIL than placebo in US studies; the differences were not clinically significant.

ECG Changes: No treatment-emergent pattern of ECG abnormalitie was found in US studies following administration of PROVIGIL. Postmarketing Reports

In addition to the adverse events observed during clinical trials, the

Tablets following adverse events have been identified during post-approval use of PROVIGIL in clinical practice. Because these adverse events are reported voluntarily from a population of uncertain size, reliable estimates of their frequency cannot be made.

Hematologic: Agranulocytosis

Central Nervous System: Symptoms of psychosis, symptoms of mania

DRUG ABUSE and DEPENDENCE: Abuse Potential and Dependence: In addition to wakefulness-promoting effect and increased locomotor activity in animals, in humans, PROVIGIL produces psychoactive and euphoric effects, alterations in mood, perception, thinking, and feelings typical of other CNS stimulants. In vitro, PROVIGIL binds to the dopamine reuptake site and causes an increase in extracellular dopamine but no increase in dopamine release. PROVIGIL is reinforcing, as evidenced by its self-administration in monkeys previously trained to self-administer cocaine. In some studies PROVIGIL was also partially discriminated as stimulant-like. Physicians should follow patients closely, especially those with a history of drug and/or stimulant (eg, methylphenidate, amphetamine, or cocaine) abuse. Patients should be observed for signs of misuse or abuse (eg, incrementation of doses or drug-seeking behavior). In individuals experienced with drugs of abuse, PROVIGIL produced psychoactive and euphoric effects and feelings consistent with other scheduled CNS stimulants (methylphenidate). Patients should be observed for signs of misuse or abuse.

Withdrawal: Following 9 weeks of PROVIGIL use in 1 US trial, no specific symptoms of withdrawal were observed during 14 days of observation, although sleepiness returned in narcoleptic patients.

OVERDOSAGE: Human Experience: A total of 151 doses of $\geq 1000 \mathrm{mg} /$ day $(5$ times the maximum recommended daily dose) have been recorded for 32 individuals. Doses of $4500 \mathrm{mg}$ and $4000 \mathrm{mg}$ were taken intentionally by 2 patients participating in foreign depression studies. In both cases, adverse experiences observed were limited, expected, and not life-threatening, and patients recovered fully by the following day. The adverse experiences included excitation or agitation, insomnia, and slight or moderate elevations in hemodynamic parameters. In neither of these cases nor in others with doses $\geq 1000 \mathrm{mg} / \mathrm{day}$, including experience with up to 21 consecutive days of dosing at $1200 \mathrm{mg} /$ day, were any unexpected effects or specific organ toxicities observed. Other observed high-dose effects in clinical studies have included anxiety, irritability, aggressiveness, confusion, nervousness, tremor, palpitations, sleep disturbances, nausea diarrhea, and decreased prothrombin time. Overdose Management: No specific antidote to the toxic effects of PROVIGIL overdose has been identified. Overdoses should be managed with primarily supportive care, including cardiovascular monitoring. Emesis or gastric lavage should be considered. There are no data suggesting that dialysis or urinary acidification or alkalinization enhance drug elimination. The physician should consider contacting a poison-control center on the treatment of any overdose.

Manufactured for: Cephalon, Inc., West Chester, PA 19380

For more information about PROVIGIL, please call Cephalon Professional Services at 1-800-896-5855 or visit our Website at WWW.PROVIGIL.com.

【C Cephalon (c) 2003 Cephalon, Inc. PR0338 Feb 2003 All rights reserved. Printed in USA. 


\section{Guide to DSM-IV ANd IGD-10 Godes}

Dementia of the Alzheimer Type, With Early Onset With Depressed Mood

Specify if: With Behavioral Disturbance

Dementia of the Alzheimer's Type, With Late Onset With Depressed Mood

Specify if: With Behavioral Disturbance

Delirium Due to: Indicate General Medical Condition

Psychotic Disorder Due to: Indicate General Medical Condition With Delusions

With Hallucinations

Mood Disorder Due to: Indicate General Medical Condition

Anxiety Disorder Due to: Indicate General Medical Condition

Amnestic Disorder Due to: Indicate General Medical Condition

Dementia NOS

Amnestic Disorder NOS

Schizophrenia

Schizophrenia-Disorganized Type

Schizophrenia-Catatonic Type

Schizophrenia-Paranoid Type

Schizophrenia-Residual Type

Schizoaffective Disorder

Schizophrenia-Undifferentiated Type

Major Depressive Disorder

Bipolar I Disorder

Bipolar Disorder NOS

Bipolar II Disorder

Mood Disorder NOS

Psychotic Disorder NOS

Autistic Disorder

Asperger's Disorder

Pervasive Developmental Disorder NOS

Anxiety Disorder NOS

Panic Disorder Without Agoraphobia

Generalized Anxiety Disorder

Dissociative Identity Disorder

Dissociative Disorder NOS

Factitious Disorder NOS

Panic Disorder With Agoraphobia

Agoraphobia Without History of Panic Disorder

Social Phobia

Specific Phobia

Obsessive-Compulsive Disorder

Dysthymic Disorder

Depersonalization Disorder

Body Dysmorphic Disorder

Somatization Disorder

Somatoform Disorder NOS

Cyclothymic Disorder

Alcohol Dependence

Cocaine Dependence

Cannabis Dependence

Amphetamine Dependence

Alcohol Abuse

Cannabis Abuse

Cocaine Abuse

Amphetamine Abuse

Stuttering

Anorexia Nervosa

Tic Disorder NOS

Tourette Disorder

Primary Insomnia

Primary Hypersomnia

Sleepwalking Disorder

Dyssomnia NOS

Nightmare Disorder

Parasomnia NOS

Eating Disorder NOS

Bulimia Nervosa

Feeding Disorders of Infancy or Early Childhood

Communication Disorder NOS

Posttraumatic Stress Disorder

Depressive Disorder NOS

Impulse-Control Disorder NOS

Pathological Gambling

Pyromania

Kleptomania

Trichotillomania

Disruptive Behavior Disorder NOS

Attention-Deficit/Hyperactivity Disorder, Combined Type

Attention-Deficit/Hyperactivity Disorder NOS

Learning Disorder NOS

Developmental Coordination Disorder

Narcolepsy

Sleep Disorder Due to: Indicate General Medical Condition

Delirium NOS
DSM-IV

290.13

ICD-10

290.21

293.0

293.81

293.82

293.83

293.89

294.0

294.8

294.8

295

295.10

295.20

295.30

295.60

295.70

295.90

296

296

296.80

296.89

296.90

298.9

299.00

299.80

299.80

300.00

300.01

300.02

300.14

300.15

300.19

300.21

300.22

300.23

300.29

300.3

300.4

300.6

300.7

300.81

300.81

301.13

303.90

304.20

304.30

304.40

305.00

305.20

305.60

305.70

307.0

307.1

307.20

307.23

307.42

307.44

307.46

307.47

307.47

307.47

307.50

307.51

307.59

307.9

309.81

311

312.30

312.31

312.33

312.34

312.39

312.9

314.01

314.9

315.9

315.4

347

780

780.09
F00.03

Foo. 13

F05.0

F06. 2

F06.0

F06

F06. 4

$\mathrm{FO} 2.8$

F03

R41.3

F20

F20.1

F20.2

F20.0

F20.5

F20.3

$\mathrm{F} 32$

F30

F39

F31. 8

F39

F29

F84

784.5

F84.9

F41.9

F41

F41.1

F44.81

F44.9

F68.1

F40.01

F 40

F 40.1

F40.2

F42.8

F34.1

F48.1

F45.2

F45.

F45.9

F34

F10.2

F14.2

F12.2

F15.2

F10.1

F12.1

F14.1

F15.1

F98.5

F50

F95.9

F95. 2

F51.0

F51.1

F51.3

F51.9

F51.5

F51.8

F50.9

F50.2

$F 98.2$

F80 9

$\mathrm{F} 431$

F 32.9

F63.9

F63.0

F63.1

F63.2

F63.3

F91.9

F90

F90.9

F81.9

$\mathrm{F} 82$

G47.4

G47

F05.9 


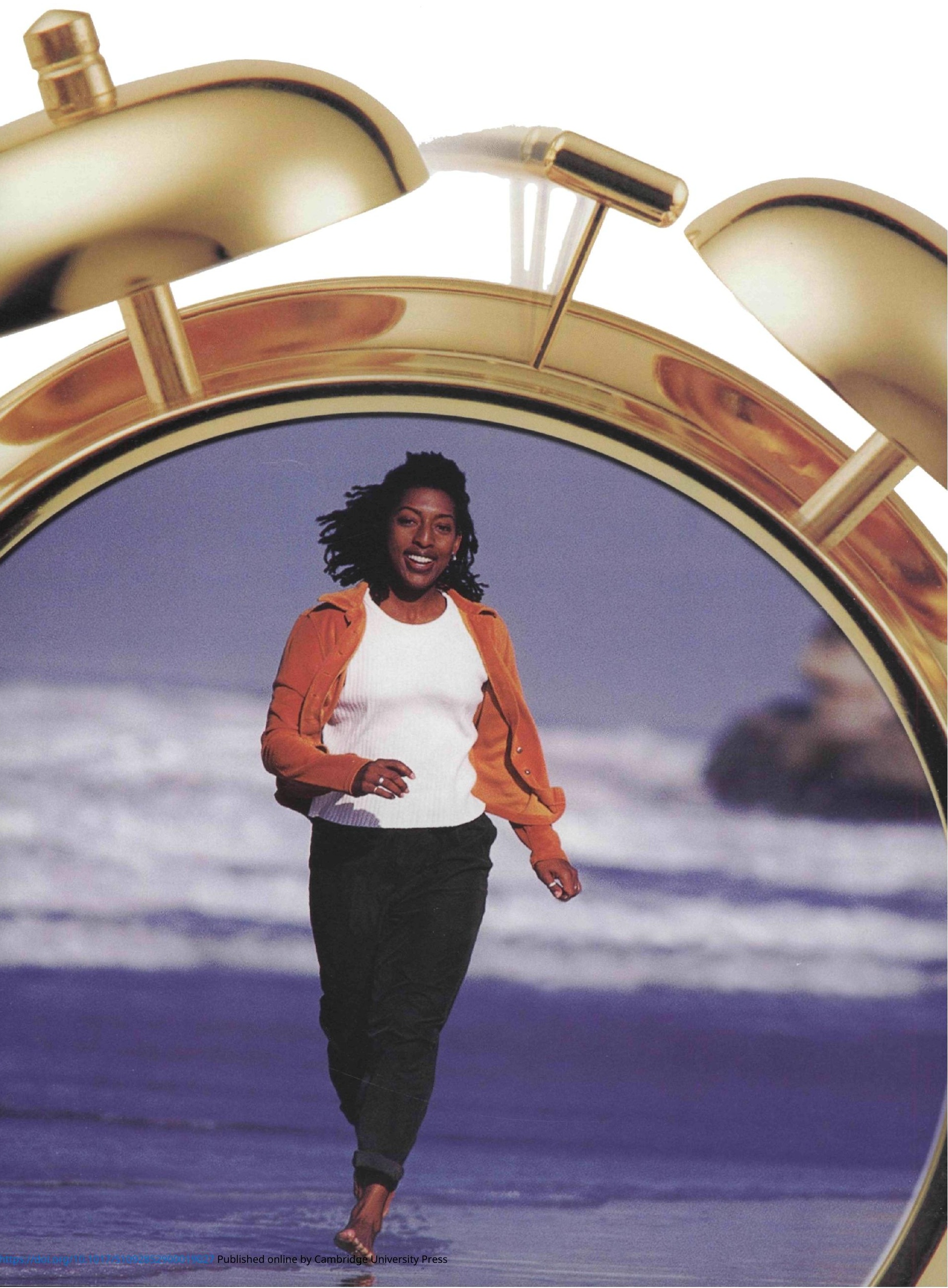




\section{Time for wakefulness}

A unique wake-promoting agent

PROVIGIL promotes daytime wakefulness, improving patients' ability to participate in daily activities-with no effect on nighttime sleep..$^{1-3}$

Long-term safety

The long-term safety profile of PROVIGIL has been demonstrated for up to 136 weeks. $^{4}$

PROVIGIL was generally well tolerated. Most frequently reported adverse events in clinical trials were headache, nausea, nervousness, anxiety, infection, and insomnia. Most adverse events were mild to moderate. PROVIGIL may interact with drugs that inhibit, induce, or are metabolized by cytochrome P450 isoenzymes.

Dosing

Recommended dose for PROVIGIL is $200 \mathrm{mg}$ taken orally once daily in the morning. Both PROVIGIL doses, $200 \mathrm{mg}$ and $400 \mathrm{mg}$ QD, were effective.

PROVIGIL is indicated to improve wakefulness in patients with excessive daytime sleepiness associated with narcolepsy.

References: 1. PROVIGIL full prescribing information. 2. US Modafinil in Narcolepsy Multicenter Study Group. Randomized trial of modafinil for the treatment of pathological somnolence in narcolepsy. Ann Neurol. 1998;43:88-97. 3. US Modafinil in Narcolepsy Multicenter Study Group. Randomized trial of modafinil as a treatment for the excessive daytime somnolence of narcolepsy. Neurology. 2000;54:1166-1175. 4. Data on file, Cephalon, Inc.

\section{PROVIGIL $(M O D A F|N| L) E$ \\ Tablets \\ Wake up to life. ${ }^{\mathrm{TM}}$}

Please see brief summary of prescribing information on adjacent page.

For more information, call 1-800-896-5855 or visit our Website at wwW.PROVIGIL.com. 


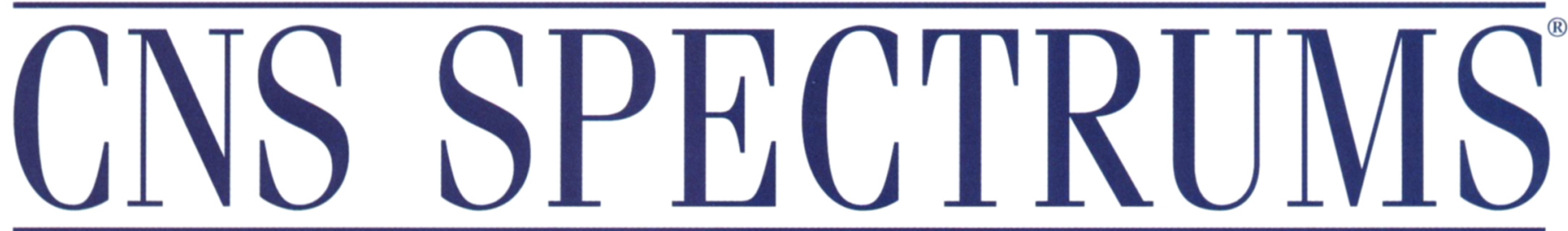

The International Journal of Neuropsychiatric Medicine

\section{EDITOR}

Jack M. Gorman, MD

Mount Sinai School of Medicine

New York, NY

\section{ASSOCIATE AND FOUNDING EDITOR \\ Eric Hollander, MD \\ Mount Sinai School of Medicine \\ New York, NY \\ INTERNATIONAL EDITOR \\ Joseph Zohar, MD \\ Chaim Sheba Medical Center \\ Tel-Hashomer, Israel}

\section{ASSOCIATE INTERNATIONAL EDITORS}

\section{EUROPE}

Donatella Marazziti, MD

University of Pisa

Pisa, Italy

\section{MID-ATLANTIC}

Dan J. Stein, MD, PhD

University of Stellenbosch

Tygerberg, South Africa

\section{FAR EAST}

Shigeto Yamawaki, MD, PhD

Hiroshima University Schoo

of Medicine

Hiroshima, Japan

\section{CONTRIBUTING WRITERS}

\section{Linda M. Bierer, MD}

Emil Coccaro, MD

Marianne Goodman, MD

Vivian Mitropoulou, MA

Larry J. Siever, MD

Daphne Simeon, MD

\section{MEDICAL REVIEWER}

David L. Ginsberg, MD

\section{BOARD OF ADVISORS}

\section{NEUROLOGISTS}

Mitchell F. Brin, MD

University of California, Irvine Irvine, CA

Jeffrey L. Cummings, MD

University of California, Los Angeles

Los Angeles, CA

Jerome Engel, Jr., MD, PhD

University of California, Los Angeles

Los Angeles, CA

Mark S. George, MD

Medical University of South Carolina Charleston, SC

Richard B. Lipton, MD

Albert Einstein College of Medicine Bronx, NY

C. Warren Olanow, MD, FRCPC Mount Sinai School of Medicine New York, NY

Steven George Pavlakis, MD

Maimonides Medical Center

Brooklyn, NY

Stephen D. Silberstein, MD, FACP

Thomas Jefferson University

Philadelphia, PA

Michael Trimble, MD, FRCP, FRPsych National Hospital for Neurology and Neurosurgery

London, United Kingdom

\section{PSYCHIATRISTS}

Margaret Altemus, MD

Cornell University Medical College

New York, NY

Dennis S. Charney, MD

National Institute of Mental Health

Bethesda, MD

Dwight L. Evans, MD

University of Pennsylvania

Philadelphia, PA

Siegfried Kasper, MD

University of Vienna

Vienna, Austria

Martin B. Keller, MD

Brown Medical School

Providence, RI
Lorrin M. Koran, MD

Stanford University School of Medicine Stanford, CA

Yves Lecrubier, MD

Hôpital de la Salpêtrière

Paris, France

Herbert Y. Meltzer, MD

Vanderbilt University Medical Center

Nashville, TN

Stuart A. Montgomery, MD

St. Mary's Hospital Medical School

London, United Kingdom

Charles B. Nemeroff, MD, PhD

Emory University School of Medicine Atlanta, GA

Humberto Nicolini, MD, PhD

National Mexican Institute of Psychiatry Mexico City, Mexico

Stefano Pallanti, MD, PhD

University of Florence

Florence, Italy

Katharine Phillips, MD

Brown Medical School

Providence, $\mathrm{R}$

Harold A. Pincus, MD

Western Psychiatric Institute \& Clinic

RAND-University of Pittsburgh Health

Institute, Pittsburgh, PA

Scott L. Rauch, MD

Massachusetts General Hospital

Charlestown, MA

Alan F. Schatzberg, MD

Stanford University School of Medicine

Stanford, CA

Stephen M. Stahl, MD, PhD

University of California, San Diego

La Jolla, California

Norman Sussman, MD, DFAPA

New York University Medical School

New York, NY

Karen Dineen Wagner, MD, PhD

The University of Texas Medical Branch

Galveston, Texas

Herman G.M. Westenberg, MD

University Hospital Utrecht

Utrecht, The Netherlands

Stuart C. Yudofsky, MD

Baylor College of Medicine

Houston, TX
MBL COMMUNICATIONS Corporate Staff

CEO \& PUBLISHER

Darren L. Brodeur

ASSOCIATE PUBLISHER

Elizabeth Katz

MANAGING EDITOR

Christopher Naccari

SENIOR EDITOR

Deborah Hughes

DEPUTY SENIOR EDITOR

José R. Ralat

ACQUISITIONS EDITOR

Lisa Arrington

\author{
ASSISTANT ACQUISITIONS EDITOR \\ Eileen S. Seligman \\ COPY EDITOR \\ Keith Papa \\ EDITORIAL ASSISTANT \\ Shelley Wong \\ PRODUCTION MANAGER \\ Lila Moses \\ GRAPHIC DESIGNER \\ Anthony J. Korsak \\ CONTROLLER \\ John Spano
}

\section{NATIONAL ACCOUNT MANAGER \\ Kelly J. Staley \\ ENDURING MATERIALS DIRECTOR \\ Chris Van Denburg \\ INFORMATION TECHNOLOGY \\ Greg Taube \\ OFFICE MANAGER \\ Claudette Crawford \\ OFFICE ASSISTANT \\ Manuel Pavón \\ CORPORATION COUNSEL \\ Lawrence Ross, Esq \\ Bressler, Amery, and Ross}

CNS Spectrums' editorial mission is to address relevant neuropsychiatric topics, including the prevalence of comorbid diseases among patients, and original research and reports that emphasize the profound diagnostic and physiologic connections made within the neurologic and psychiatric fields. The journal's goal is to serve as a resource to psychiatrists and neurologists seeking to understand and treat disturbances of cognition, emotion, and bebavior as a direct consequence of central nervous system disease, illness, or trauma. 


\section{Author Guidelines}

\section{Introduction}

CNS Spectrums is an Index Medicus journal that publishes original scientific literature and reviews on a wide variety of neuroscientific topics of interest to the clinician. CNS Spectrums will publish 12 issues in 2003. As the immense prevalence of comorbid diseases among patients seen by psychiatrists and neurologists increases, these physicians will jointly diagnose and treat the neuropsychiatrically ill. Our mission is to provide these physicians with an editorial package that will enhance and increase their understanding of neuropsychiatry; therefore, manuscripts that address crossover issues germane to neurology and psychiatry will be given immediate priority.

\section{Scope of Manuscripts}

CNS Spectrums will consider the following types of articles for publication:

Original Research: Original Research presents methodologically sound original data.

Reviews: Reviews are comprehensive articles that summarize and synthesize the literature on various topics in a scholarly and clinically relevant fashion. Suitable topics include mood disorders, schizophrenia and related disorders, personality disorders, substance-use disorders, anxiety disorders, neuroscience, psychosocial aspects of psychiatry, child psychiatry, geriatric psychiatry, and other topics of interest to clinicians. Original flowcharts designed to aid the clinician in diagnosis and treatment will be considered for publication in reviews and are encouraged.

Case Reports: Single or multiple case reports will be considered for publication.

Letters to the Editor: Letters will be considered for publication.

\section{Manuscript Submission}

General information: Two copies of the manuscript with a letter on the author's letterhead should be submitted to Jack M. Gorman, Editor (or, in Europe, to Joseph Zohar, International Editor), c/o MBL Communications, 333 Hudson Street, 7th Floor, New York, NY 10013; (F) 212.328.0600. Authors are also required to submit their manuscripts on computer disk in Microsoft Word format. Disks should be labeled with the word processing program, title of paper, and lead author's name. Accepted manuscripts and letters will be edited for clarity and style.

Letters of permission to reproduce previously published material: All material reproduced from previously published copyrighted material must be accompanied by a letter of permission from the copyright holder. All such material should include a full credit line (eg, in the figure or table legend) acknowledging the original source. Any citation of unpublished material or personal communication should also be accompanied by a letter of permission for anyone who is not an author of the paper.

Peer review: Authors must provide five names of particularly qualified potential reviewers with no conflict of interest in reviewing the work. Contact information, including complete address, phone, fax numbers, E-mail address, and affiliations, should be included. The corresponding author will be notified by the editors when a decision regarding acceptance has been made. Peer review is anonymous.

\section{Manuscript Preparation}

Length: Reviews and Original Research should not exceed 5,000 words (excluding References). Letters should not exceed 1,500 words. Single Case Reports should not exceed 3,750 words and may be submitted with a photograph, if applicable. Diagnostic/treatment algorithms (see Reviews) should contain an extensive introduction, flowchart or series of graphs that fill 8-12 journal pages, and a concise summary.

Please note: If your article is Original Research, it should be formatted as: Abstract (100-200 words); Introduction, Methods; Findings; Discussion; Conclusion; References (numbered and comprehensive list).

Spacing: One space should be left after commas and periods. Manuscripts should be double-spaced.

Abstract: Authors must provide a brief abstract.

Focus/Talking Points: Please provide three to six points that dictate the main focus of the manuscript, similar to teaching objectives, in bulleted format. These take-home points should clearly illustrate what you are trying to convey in the article.

References: American Medical Association style. See the following examples:

1. Jones J. Necrotizing Candida esophagitis. JAMA. 1980;244:2190-2191.

2. Stryer L. Biochemistry. 2nd ed. San Francisco, Calif: WH Freeman Co; 1980:559-596.

Continuing Medical Education: Authors must submit six multiple-choice questions (three Type $A$ and three Type $K$ ), with answers.

Copyright: Materials are accepted for exclusive publication in $C N S$ Spectrums and become the property of CNS Spectrums. Permission to reproduce material must be obtained from the publisher.

\section{Disclosure of Commercial Interests}

Authors must include a statement about all forms of support, including grant and drug company support. Such information may, at the editor's discretion, be shared with reviewers. If the article is accepted for publication, the editors will consult with the authors as to whether this information should be included in the published paper.

\section{Submission Checklist}

$\square$ Original manuscript plus one copy, with cover letter on author's letterhead

$\square$ Copies of permission letters to reproduce previously published and unpublished material

A brief abstract of the article

Six CME multiple-choice questions with answers

$\square$ Three to six focus points

Disk labeled with the word processing program, title of paper, and lead author's name

$\square$ Names and addresses of five potential reviewers 


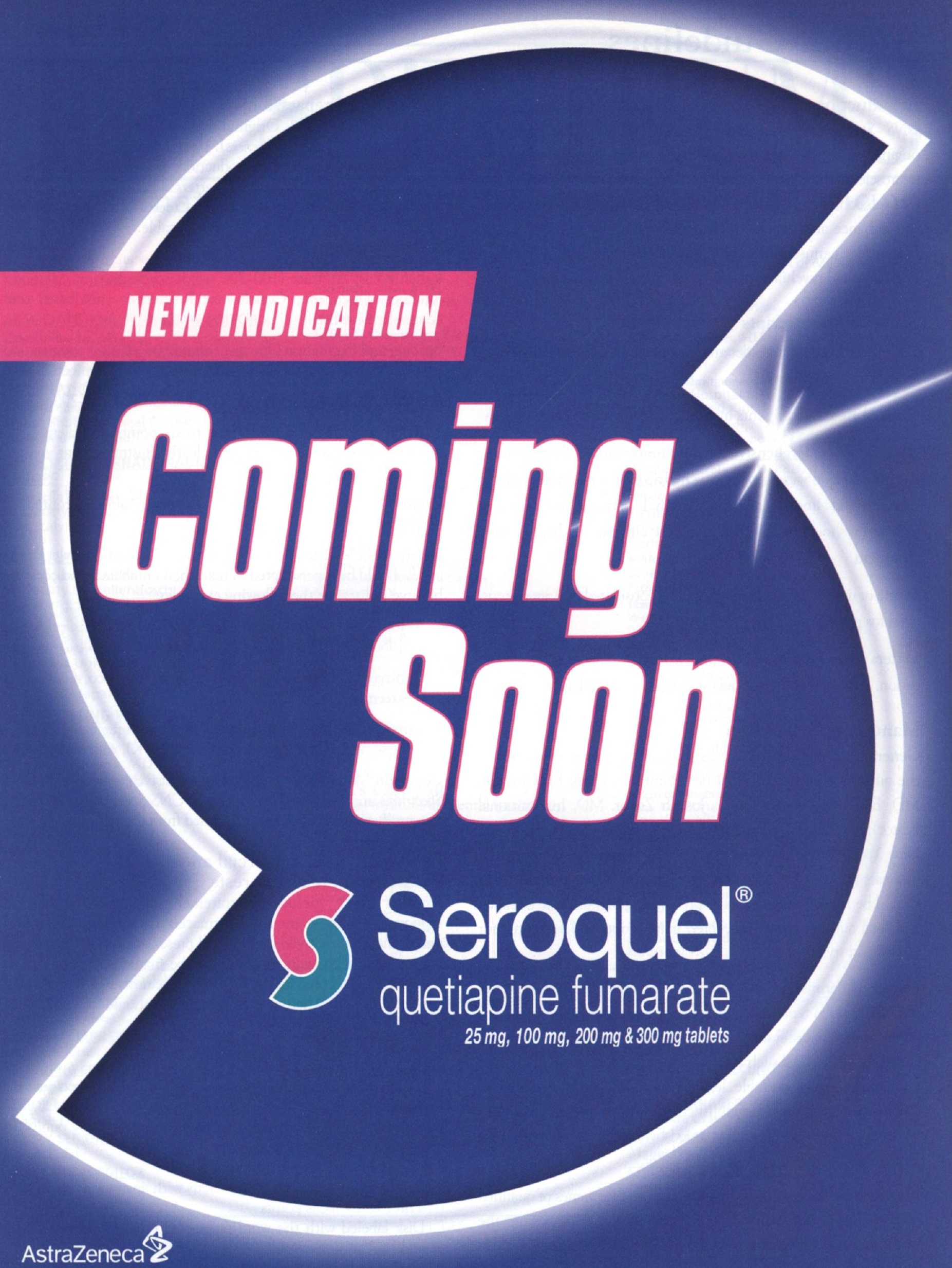




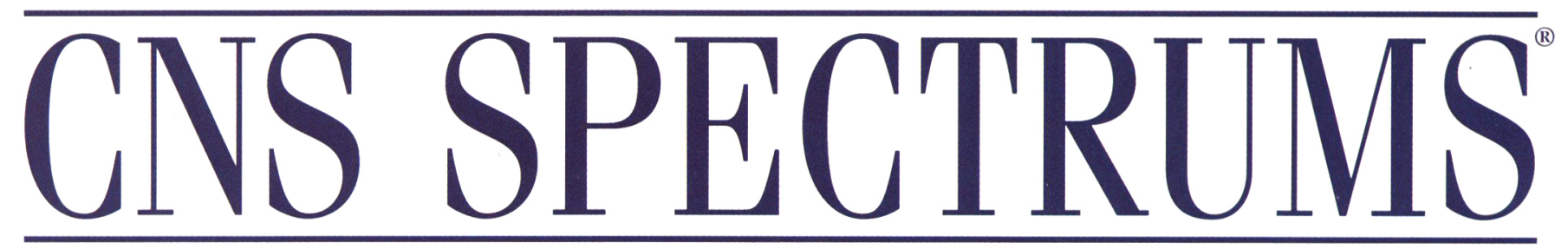

The International Journal of Neuropsychiatric Medicine

\section{Table of Contents}

October 2003

Volume 8 - Number 10

\section{Feature Articles}

INTRODUCTION

724 Refining the Approaches to Personality Disorders

By Larry J. Siever, MD

ORIGINAL RESEARCH

725 Neurobiologic Function and Temperment in Subjects

With Personality Disorders

By Vivian Mitropoulou, MA, Robert L. Trestman, PhD, MD,

Antonia S. New, MD, Janine D. Flory, PhD,

Jeremy M. Silverman, PhD, and Larry J. Siever, MD

\section{ORIGINAL RESEARCH}

737 Abuse and Neglect in Childhood: Relationship to

Personality Disorder Diagnoses

By Linda M. Bierer, MD, Rachel Yehuda, PhD,

James Schmeidler, PhD, Vivian Mitropoulou, MA,

Antonia S. New, MD, Jeremy M. Silverman, PhD,

and Larry J. Siever, MD

\section{CME-Accredited Articles}

\section{ORIGINAL RESEARCH}

731 Norepinephrine Function in Personality Disorder:

Plasma Free MHPG Correlates Inversely With Life History of Aggression

By Emil F. Coccaro, MD, Royce Lee, MD,

and Michael McCloskey, PhD

\section{ORIGINAL RESEARCH}

755 Relationship of Personality to Dissociation and Childhood

Trauma in Borderline Personality Disorder

By Daphne Simeon, MD, Dorothy Nelson, BSc, Rachela Elias, BA, Jennifer Greenberg, BA, and Eric Hollander, MD

\section{ORIGINAL RESEARCH}

763 The Role of Childhood Trauma in Differences in Affective

Instability in Those With Personality Disorder

By Marianne Goodman, MD, Daniel S. Weiss, PhD,

Harold Koenigsberg, MD, Vladimir Kotlyarevsky, MS,

Antonia S. New, MD, Vivian Mitropoulou, MA,

Jeremy M. Silverman, PhD, Karen O’Flynn, MD, and Larry J. Siever, MD

Founded in 1996, CNS Spectrums

is an Index Medicus journal

and is available on MEDLINE

under the citation CNS Spectr.

It is also indexed by DIALOG, EMBASE/Excerpta Medica, Lexis-Nexis, OVID, and SilverPlatter.

CNS Spectrums is the official educational journal of the International Association for Women's Mental Health.

CNS Spectrums is available online at wWW.cnsspectrums.com

\section{CNS Spectrums ${ }^{\circledast}$}

(ISSN 1092-8529)

is published monthly by

MBL Communications, Inc.

333 Hudson Street, 7th Floor

New York, NY 10013

One-year subscription rates:

domestic \$120;

foreign $\$ 185$;

in-training $\$ 75$.

For subscriptions:

Fax 212-328-0600

or visit our Web site:

www.cnsspectrums.com

Postmaster:

Send address changes to

CNS Spectrums

clo PPS Medical Marketing Group

264 Passaic Avenue

Fairfield, NJ 07004-2595 


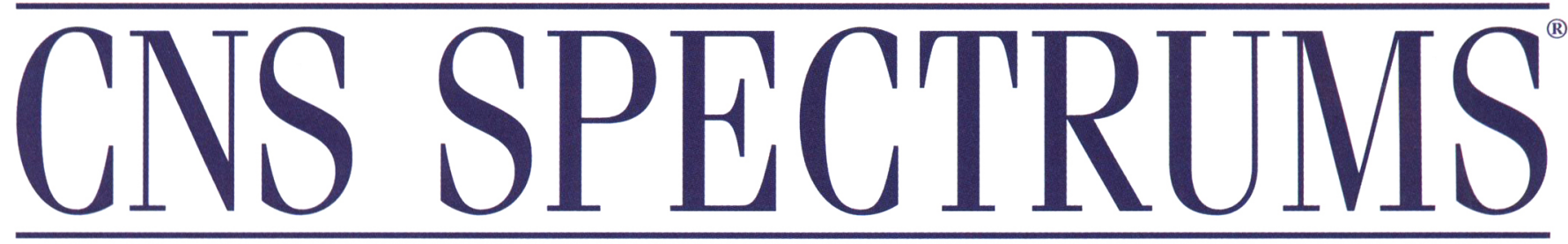

The International Journal of Neuropsychiatric Medicine

\section{Table of Contents}

October 2003

Volume 8 - Number 10

\section{Departments/Monthly Columns}

\section{FROM THE EDITOR'S DESK}

716 From Neuroses to Neuropsychiatry: Replacing Adjectives With Science in the Study of Personality Disorders

By Jack M. Gorman, MD

\section{CLINICAL UPDATES IN NEUROPSYCHIATRY}

717 News From the Field of Neuroscience

- New Screening Method Accurately Detects Migraines

- Second Gene Implicated in Joubert Syndrome

- Long-Term Results of Epilepsy Surgery Suggest

Positive Outcome

- Working Memory Possibly Improved by Creatine Usage

- Supplemental New Drug Application for Ropinirole for Restless Legs Syndrome

- FDA Approves Vardenafil for the Treatment of Erectile Dysfunction

- FDA Approves Bupropion Extended-Release for Major Depressive Disorder

\section{CONTINUING MEDICAL EDUCATION}

773 This CME quiz on personality disorders is accredited by Mount Sinai School of Medicine for 3.0 credit hours in Category 1.

\section{DIRECTORY OF SERVICES}

708 Guide to DSM-IV and ICD-10 Codes

711 Author Guidelines

777 Editorial Questionnaires

779 Subscriptions

780 Author Guidelines
For editorial inquiries, please fax us at 212-328-0600 or e-mail us at jrr@mblcommunications.com.

For advertising inquires, please fax us at 212-328-0600 or e-mail us at: ek@mblcommunications.com kjs@mblcommunications.com. For bulk reprint purchases, please contact: Kelly J. Staley at kjs@mblcommunications.com Opinions and views expressed by authors are their own and do not necessarily reflect the views of the publisher, MBL Communications, Inc., or the editorial advisory board.

Advertisements in CNS Spectrums are accepted on the basis of adherence to ethical medical standards, but acceptance does not imply endorsement by CNS Spectrums or the publisher. CNS Spectrums ${ }^{\circledR}$ is a registered trademark of CNS Spectrums, LLC, New York, NY.

Permission to reproduce articles in whole or part must be obtained in writing from the publisher.

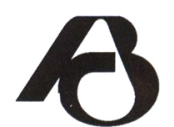

Audit Bureau of Circulations MEM B E R SINCE 20001

Copyright $@ 2003$ by MBL

Communications, Inc. All rights reserved. Printed in the United States. 


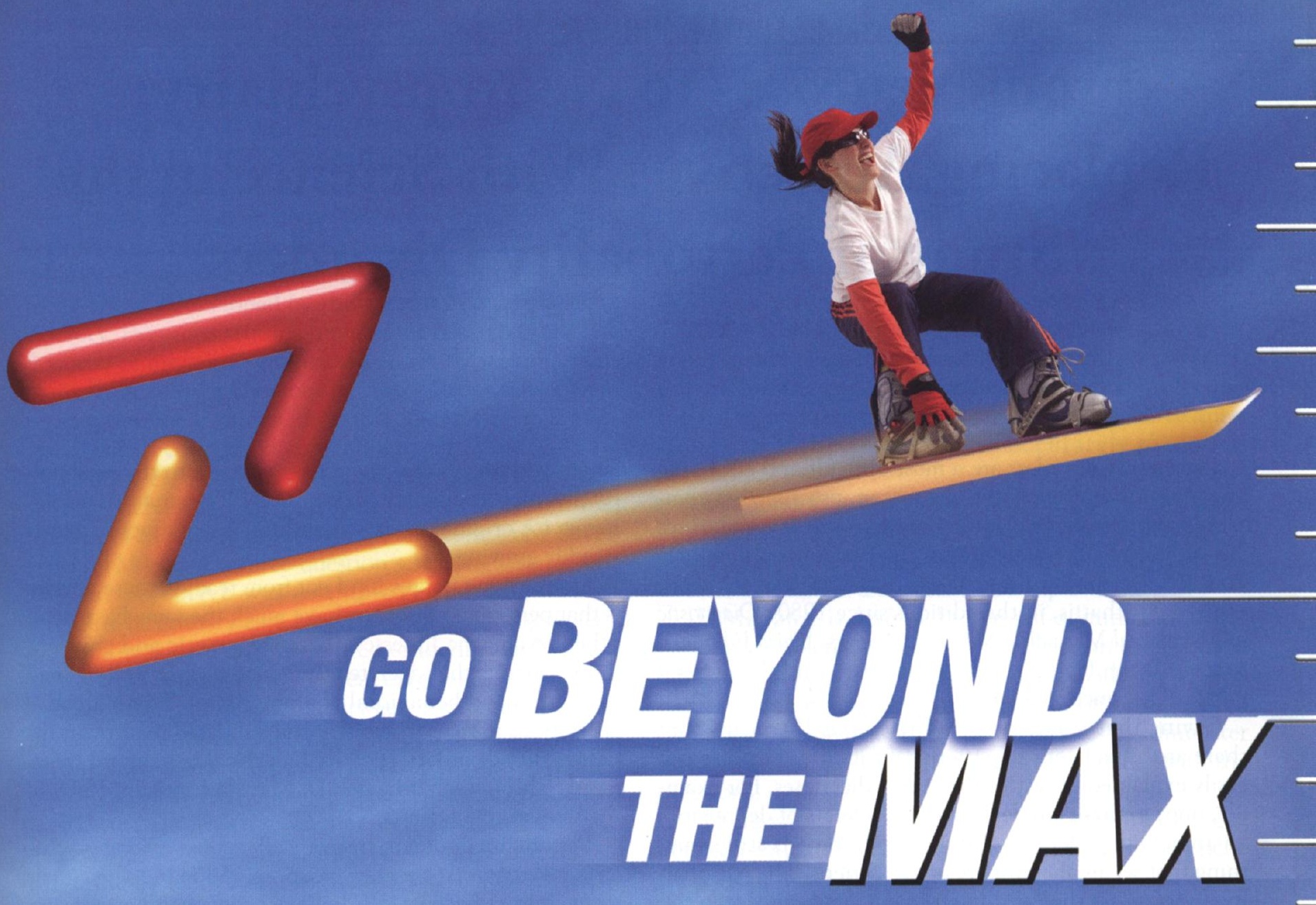

